\section{Fixation of Mitochondria}

THE importance of always omitting lipide solvents from fixatives for mitochondria has, I think, been exaggerated. I find that mitochondria are readily demonstrable in the liver of the newt and the kidney of the mouse even after fixation with Carnoy's alcoholchloroform-acetic, which should certainly remove all lipides. Bouin's fluid preserves the mitochondria in the liver of the newt as well as the standard mitochondrial fixatives. When in Dalmatia in the summer I put the testes of some Hemiptera (Syromastes marginatus) into Bouin's fluid and left them in it until my return to England. On sectioning them I found the filamentous mitochondria of the primary spermatocytes well preserved.

Although mitochondria are in certain cases preserved by these methods, they are not thereby mordanted for subsequent staining. It is best to bring the sections to water and then leave them overnight in three per cent potassium dichromate in a paraffin oven. Next morning they are washed in running water for five minutes, and then stained by Altmann's technique or one of its modifications.

Champy $^{2}$ mentioned in 1911 that mitochondria are sometimes preserved by Bouin's fluid, and Romeis $^{3}$ in 1913 saw them, somewhat distorted, after Carnoy's fluid without chloroform. It seems that when there is a large protein component in mitochondria, there is no necessity to omit acetic acid and lipide solvents from fixatives used to show them.

I wish to retract my recently published remarks ${ }^{1}$ on the fixative action of quinone. I placed tissues in quinone solutions and then transferred them to Carnoy's fluid. Mitochondria were not dissolved. In view of the current opinion regarding the action of Carnoy's fluid on mitochondria, I concluded that quinone was a powerful fixative for them. It is now clear that the evidence for this conclusion was insufficient.

University Museum, Oxford.

JOHN R. BAKER.

\section{Oct. 8.}

'Baker. J. R., NATURE 130, 134, July 23, 1932.

3 Romeis, B., Arch. mikr. Anat., 81, p. 129 ; 1913.

Factors Determining the Distribution of Apion ulicis

Is connexion with the noxious weed control investigations at Farnham Royal Laboratory on behalf of the New Zealand Government, an experiment has been carried out in order to throw light upon the nature of the factors limiting the distribution of Apion ulicis; for this weevil is not found throughout the areas occupied by its host plant, Ulex europoeus. Its abundance on the Moray coast, for example, and its absence from the Aberdeen district suggest the possibility that climatic factors in the north may only be suitable in the warmer districts.

The experiment consisted of the introduction of 25,500 mature insects, beaten off bushes, to an island in the River Don near its mouth at Bridge of Don, Aberdeen. This island is several acres in extent and has many large clumps of gorse upon it. Careful search was made previously to ascertain that no Apion ulicis was there. In November 1929, 500 Apions, collected from Nairn, were liberated; in January 1930, 5,000 from Buckinghamshire were liberated, and in April 1930 Dr. Guy Morrison liberated 20,000 from Buckinghamshire after making another search on the island for Apion and finding none. The gorse was in full bloom at the time of this last liberation. In April 1931 half an hour's beating of the bushes resulted in the finding of 15 live specimens of Apion, so that a considerable number must have survived the winter. In August 1932 another search was made and although only one dead Apion was beaten off the bushes, there were well developed Apion larvæ in four pods out of 300 examined, the total number of pods present being probably 1-200,000. Thus there is evidence that both winters must have been survived by many of the weevils and that normal breeding had taken place this year and probably last year also.

It may be, then, that the limited distribution of Apion ulicis is attributable to inadequate dispersal, but observations over a longer period are necessary before it can be definitely attributed to this cause rather than to the occurrence of occasional devastating conditions, such as long-continued low temperatures during the breeding season.

Dept. of Botany,

University College of Wales, Aberystwyth.

\section{Undeciphered Scripts}

RefERRING to the note in NATURE of October 1, p. 502, on the similarity of ancient scripts found in the Indus Valley and in Easter Island, it may be mentioned that Prof. Herman Wirth, of Marburg, has also directed attention to a number of similar symbols that have been found in North and South America, Sweden, Southern Andalusia, Mesopotamia, Africa and Oceania. He explains some of these signs on the usual lines of literal interpretation; but the fact that so many ideographs, "even [!] the Svastica" as Sir Denison Ross observes, are found in diverse parts of the world suggests that a certain class of archaic symbol cannot be interpreted as mere pictographs of material objects and local events. They obviously constitute the elements of a universal 'language' the symbols of which represent functions of Nature. The practical scientific knowledge of prehistoric civilisations implies some familiarity with the operations of the dual, positive and negative principle in Nature.

The knowledge of the physicist and biologist, hitherto neglected in palæographical research, may be required for the interpretation of some of these undeciphered 'scripts'. The geometrical and algebraical 'functions' of stresses, strains, and trans. formations of 'lines of force', do not vary from age to age; and, although the symbols for these in one era may seem abitrary to the savants of another age, the man of science is much more likely to find the 'key' than the man of letters.

W. W. L.

\section{Photochemical Synthesis of Vitamin $\mathbf{B}_{1}$ [BY CABLE]}

ADENINE SULPHATE has been activated into vitamin $B_{1}$ by irradiation with ultra-violet light. Guanine chloride could not be activated similarly. Tests were carried out on rats according to the technique previously described. Details will appear elsewhere.

B. C. GUHA,

P. N. Chakravorty.

Biochemical Laboratory,

Bengal Chemical and Pharmaceutical Works, Ltd., Calcutta, Nov. 7.

No. 3289, VoL. 130] 